\title{
Pattern of Lumbar MRI Changes in Patients with Chronic Low Back Pain in a Tertiary Care Center
}

\author{
Rupesh Sharma ${ }^{\mathrm{a}, \mathrm{d}}$ Awadhesh Tiwari ${ }^{\mathrm{b}, \mathrm{d}}$ Rajeev Dwivedi ${ }^{\mathrm{c}, \mathrm{d}}$
}

\begin{abstract}
:
Introduction: Chronic low back pain (LBP) is a common cause of disability worldwide. Magnetic resonance imaging (MRI) is an excellent non-invasive imaging modality for morphologic evaluation of the lumbar spine in patients with chronic low back pain because of its high contrast resolution and lack of ionizing radiation. This study was done to see the patterns of MRI changes in patients with chronic low back pain in a tertiary care center in Western Nepal. Methods: This was a cross-sectional study conducted on patients presenting with chronic low back pain. Eleven MRI parameters were noted and analyzed. Chi square test and Fisher's Exact test were employed to see the associations between the various MRI findings. Results: A total of 108 patients were evaluated during the study period. MRI changes were noted in over $95 \%$ of the cases. Degenerative changes were the most common cause of low back pain, disc bulge being the most common MRI finding. A significant association was found between radiculopathy and decreased lumbar lordosis and vertebral endplate changes. Conclusion:MRI is an invaluable tool in the evaluation of chronic LBP because of its high resolution and lack of ionizing radiation. Significant MRI findings are noted in most of the cases of chronic LBP, degenerative changes being the most common and ranging from congenital to malignant lesions.
\end{abstract}

Keywords: Low Back Pain, MRI, Radiculopathy, LS Spine

\section{INTRODUCTION:}

Low Back Pain (LBP) is defined as the pain below the costal margin and above the inferior gluteal fold, with or without radiculopathy, and is called chronic if persists for three months or more. [1] Globally, LBP ranks the highest in terms of disability and sixth in terms of overall burden with point prevalence of $9.4 \%$.[2]In Nepal, the overall prevalence of LBP is $57.1 \%$ and that of chronic LBP is $16.4 \%$.[1] The differential diagnoses of LBP include mechanical LBP (most common, 97\%), nonmechanical LBP (1\%) and visceral disease (2\%). Of

\footnotetext{
Submitted: 11 November, 2018

Accepted: 17 December, 2018

Published: 29 December, 2018

a - Lecturer, Department of Radiodiagnosis

b - Associate Professor and Head, Department of Radiodiagnosis

c - Associate Professor and Head, Department of Orthopaedics

d - Lumbini Medical College and Teaching Hospital, Pravas, Palpa

Corresponding Author:

Rupesh Sharma

e-mail: roopskarma@gmail.com

ORCID: https://orcid.org/0000-0002-3422-6150
}

the mechanical LBP, about $70 \%$ includes sprain and strain and 10\% includes degenerative changes.[3]

Magnetic resonance imaging (MRI) is an excellent non-invasive imaging modality for morphologic evaluation of lumbar spine because of its high contrast resolution and lack of ionizing radiation. [4,5] It is a routinely prescribed investigation for chronic LBP worldwide and in Nepal likewise. A number of spine changes including vertebral, disc and paravertebral changes have been found to be associated with chronic LBP and are best depicted in MRI.

However, very few studies on MRI findings of chronic LBP have been published based on Nepalese population. This study was therefore undertaken to study the patterns of lumbar MRI changes in Nepalese population attending Lumbini Medical College and Teaching Hospital (LMCTH), Palpa with chronic LBP.

\section{How to cite this article:}

Sharma R, Tiwari A, Dwivedi R. Pattern of Lumbar MRI Changes in Patients with Chronic Low Back Pain in a Tertiary Care Centre Journal of Lumbini Medical College. 2018;6(2):5 pages. DOI: 10.22502/ jlmc.v6i2.273. Epub: 2018 Dec 29. 


\section{METHODS:}

This was a cross-sectional study based on convenience sampling, comprising of patients attending LMCTH, Palpa with complaint of LBP for at least three months. The sample size was calculated taking into consideration the prevalence of chronic LBP of $16.4 \%$ in Nepal with a $10 \%$ margin of error, which totaled to a minimum of 53 cases. The study, after being approved by the Institutional Review Committee (IRC-LMC), was carried out over a period of 12 months from September 2016 to August 2017 comprising a total of 108 cases.

Only the patients with LBP for at least three months and referred to the department of Radiodiagnosis for MRI lumbo-sacral (LS) spine were enrolled, after informed consent. Patients with general contraindications to MRI such as presence of prosthetic heart valves, metallic clips and implants, claustrophobia and those with past history of surgical procedures in the spine were excluded from the study.

The MRI studies were done in the Department of Radiodiagnosis, LMCTH using a 0.35 Tesla Siemens MagnatomTM MRI Scanner by a qualified technician. Axial, coronal and sagittal images in T1 weighted, T2 weighted and Short T1 Inversion Recovery (STIR) sequences were routinely done with gadolinium-enhanced study whenever deemed necessary.

The data recorded for analysis included demographics, clinical findings and MRI findings. The clinical findings included the duration and presence or absence of radiculopathy. MRI findings primarily included a total of 11 variables, viz. LS angle, lumbar lordosis, intervertebral disc (IVD) signal, disc size, disc bulge, disc herniation, annular tear, vertebral endplate changes, vertebral foraminal narrowing, spinal canal narrowing and ligamentum flavum thickness. Other lesions such as neoplastic, congenital, traumatic and infective lesions were recorded when present. Apart from the altered LS angle and lumbar lordosis, rest of the findings represent the degenerative changes.[6] LS angle $>45$ degrees was considered as increased.[7] Lumbar lordosis was calculated as per the modified Cobb's angle and considering the superior endplates of L1 and S1 vertebrae.[8] Loss of IVD signal was considered when the T2 signal intensity of the disc was lost. Endplate changes were categorized as per Modic changes.[9] The displacement of disc tissue beyond the edges of ring apophysis was defined as the herniation if it was $<50 \%$ and termed as bulge if $>50 \%$. Disc herniation was further divided as protrusion, extrusion and sequestration. The herniated disc was labelled as protrusion if the width of the base was larger than the largest diameter of the disc material beyond the normal margin and it was labelled as extrusion otherwise. If the extruded part of the disc lost the continuity with the parent disc, it was then called as sequestration. Spinal canal diameter of at least $13 \mathrm{~mm}$ was considered normal.

The data were entered to excel spreadsheet and analyzed using Statistical Package for Social Sciences (SPSS ${ }^{\mathrm{TM}}$ ) version 16. The descriptive results were presented in terms of mean, standard deviation, frequency and percentage. Chi square test and Fisher's Exact test were employed for the analysis of categorical data. $p$ value of less than 0.05 was considered statistically significant.

\section{RESULTS:}

Altogether 142 patients underwent MRI LS spine during the study period, out of which 34 were excluded because the duration of LBP was less than three months. Thus a total of 108 patients with chronic LBP were included. The age of the patients ranged from 12 to 82 years with a mean age $( \pm \mathrm{SD})$ of 44.5 years $( \pm 16.3)$. A total of $56(51.9 \%)$ males and $52(48.1 \%)$ females constituted the study population. Radiculopathy was present in 52 (48.1\%) patients.

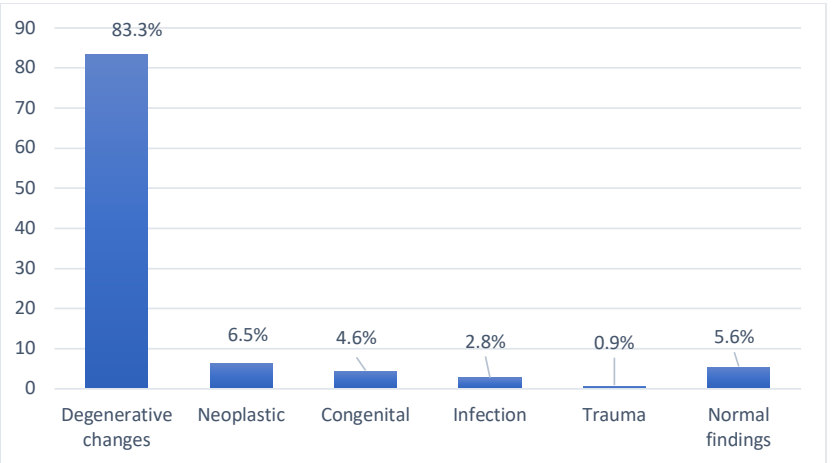

Fig. 1. Spectrum of spinal pathologies in MRI findings of patients with chronic $L B P$

The most common pathology was degenerative changes $(83.3 \%)$ followed by neoplastic lesions (6.5\%) and congenital conditions (4.6\%) (Fig 1). Some of the patients had more than one spinal 
Table 1. MRI findings of LS spine in the study population ( $n=108)$

\begin{tabular}{lcc}
\hline MRI findings & No. of cases & Percentage \\
\hline Disc signal change & 90 & 83.3 \\
\hline Disc bulge & 84 & 77.8 \\
\hline Foraminal narrowing & 83 & 76.9 \\
\hline Loss of lumbar lordosis & 55 & 50.9 \\
\hline Spinal canal narrowing & 53 & 49.1 \\
\hline Disc herniation (n=42) & & \\
$\quad$ Protrusion & 27 & 25 \\
\multicolumn{1}{l}{ Extrusion } & 13 & 12 \\
\hline \multicolumn{1}{l}{ Sequestration } & 2 & 1.9 \\
\hline Decreased disc size & 38 & 35.2 \\
\hline Increased L-S angle & 25 & 23.1 \\
\hline Annular tear & 23 & 21.3 \\
\hline Thickened ligamentum flavum & 18 & 16.7 \\
\hline Endplate change & 17 & 15.7 \\
\hline
\end{tabular}

pathology.

The most common MRI finding was disc signal change $(83.3 \%)$ followed by disc bulge $(77.8 \%)$ and foraminal narrowing $(76.9 \%)$ (Table 1$)$.

In this study, disc protrusion was the most common type of disc herniation (Table 1). Out

Table 2. Associations between radiculopathy and MRI findings

\begin{tabular}{llc}
\hline Variable & MRI finding & \multicolumn{1}{c}{ Statistics } \\
\cline { 2 - 3 } Loss of lumbar & $\mathrm{X}^{2}(\mathrm{df}=1, \mathrm{~N}=108)$ \\
& lordosis & $=6.306, \mathrm{p}=0.012$ \\
Radiculopathy & Endplate changes & $\mathrm{X}^{2}(\mathrm{df}=1, \mathrm{~N}=108)$ \\
$=6.518, \mathrm{p}=0.038$ \\
& $\begin{array}{l}\text { Foraminal } \\
\text { narrowing }\end{array}$ & $\mathrm{X}^{2}(\mathrm{df}=1, \mathrm{~N}=108)$ \\
& $\begin{array}{l}\text { Spinal canal } \\
\text { narrowing }\end{array}$ & $\mathrm{X}^{2}(\mathrm{df}=1, \mathrm{~N}=108)$ \\
$=4.459, \mathrm{p}=0.035$ \\
\hline
\end{tabular}

of these, postero-lateral herniation was the most common and foraminal was the least common.

Table 3. Associations between ligamentum flavum thickening and MRI findings

\begin{tabular}{llc}
\hline Variable & MRI finding & Statistics \\
& $\begin{array}{l}\text { Foraminal } \\
\text { narrowing }\end{array}$ & $\mathrm{p}=0.011^{*}$ \\
$\begin{array}{l}\text { Ligamentum } \\
\text { flavum } \\
\text { thickening }\end{array}$ & $\begin{array}{l}\text { Spinal canal } \\
\text { narrowing }\end{array}$ & $\begin{array}{c}\mathrm{X}^{2}(\mathrm{df}=1, \mathrm{~N}=108) \\
=4.631, \mathrm{p}=0.031\end{array}$ \\
& Decreased disc size & $\begin{array}{r}\mathrm{X}^{2}(\mathrm{df}=1, \mathrm{~N}=108) \\
=6.366, \mathrm{p}=0.012\end{array}$ \\
\hline F
\end{tabular}

* Fisher's Exact test.
Scoliosis was the most common congenital lesion followed by lumbosacral transitional vertebra and Tarlov cyst.

We also observed significant association between radiculopathy and loss of lumbar lordosis, endplate changes, spinal and foraminal narrowing (Table 2). Similarly, ligamentum flavum thickening was found to be significantly associated with foraminal narrowing, spinal canal narrowing and decreased disc size (Table 3). Ligamentum flavum thickening was not found in age less than 26 years and the incidence of lumbar lordosis was more in females.

\section{DISCUSSION:}

With an overall increase in life expectancy and more patients attending tertiary care hospitals in recent days for LBP, MRI has become an important diagnostic tool for the evaluation of LS spine. This study was done to evaluate the pattern of MRI changes in cases of chronic LBP.

More than $95 \%$ of the patients with chronic LBP had some form of abnormal MRI findings in LS vertebra. The most common finding was degenerative changes $(83.3 \%)$, similar to many other studies. $[10,11,12,13]$ Disc signal change was the most common finding (83.3\%), followed by some form of prolapsed intervertebral disc (PIVD), namely diffuse disc bulge (77.8\%) and disc herniation (38.9\%) in that 


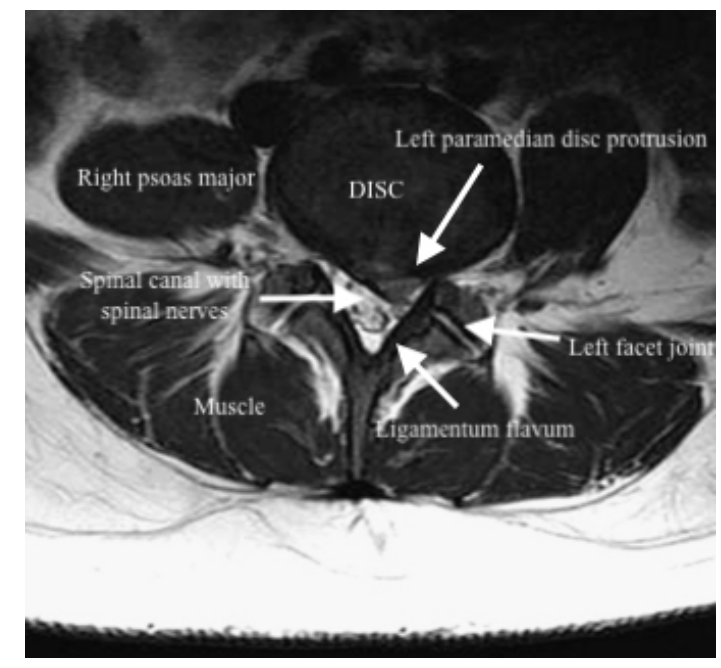

Fig 2. MRI T2 axial showing a left paramedian disc protrusion at L4-5 IVD level causing narrowing of left neural foramina.

order. This observation is similar to that by Ansari et al.[13] in a study based on Nepalese population. In another study from India, disc bulge was the most common form of PIVD followed by disc herniation; posterolateral herniation being the most common type.[10]However in a study done in Ethiopia the most common form of PIVD was disc herniation followed by disc bulge.[11] This difference may be because of the difference in the population studied. Ogon et al.[14]reported a significant association between IVD signal change and chronic LBP which supports our observation of disc signal change being the most common MRI finding. In a study done by Rachel A et al.[15], significant MRI findings were found in patients with radiculopathy as was seen in our study.

Ligamentum flavum is intimately related to the spinal canal posteriorly (Fig 2). Age related degenerative changes and mechanical stress have been implicated as the possible mechanisms for thickening of ligamentum flavum.[16] In our study, the ligamentum flavum thickening was found to be significantly associated with spinal canal and foraminal narrowing which was also shown in a study by Saleem et al.[17]

The most common neoplasia was vertebral hemangioma seen in five cases (4.6\%) which is similar to another large scale study done in Nepal. [12] The youngest patient in our study was a 12 years boy, a known case of leukemia, with LBP for eight months. MRI finding was however unremarkable. Scoliosis was the most common congenital spinal condition in this study similar to a study done in India.[10]
This study was done in a single center using a 0.35 Tesla MRI machine. However, 1.5 Tesla MRI has now become the standard in which the image resolution is relatively better with higher signal-tonoise ratio (SNR). Thus a larger population based multi-centre study with 1.5 Tesla (or higher) MRI will be a better study. Also since studies have shown abnormal MRI findings in cases with no LBP[18], a case-control study would yield a better study result.

\section{CONCLUSION:}

MRI is an invaluable tool in the evaluation of chronic LBP because of its high resolution and lack of ionizing radiation. Significant MRI findings are noted in most of the cases of chronic LBP, degenerative changes being the most common and ranging from congenital to malignant lesions.

\section{Conflict of interest:}

None Declared.

\section{Financial Disclosure:}

No funds were available. 


\section{REFERENCES:}

1. Chou R. Low back pain (chronic). BMJ clinical evidence. 2010 Oct 8;2010:1116.PMID: 21418678 [Publisher Full Text]

2. Hoy D, March L, Brooks P, Blyth F, Woolf A, Bain C, et al. The global burden of low back pain: estimates from the Global Burden of Disease 2010 study. Annals of the Rheumatic Diseases. 2014 Jun 1;73(6):968-74. PMID: 24665116 doi:10.1136/annrheumdis-2013-204428

3. Deyo RA, Weinstein JN. Low back pain. New England Journal of Medicine. 2001 Feb 1;344(5):363-70. PMID: 11172169 DOI: 10.1056/NEJM200102013440508

4. Suthar P, Patel R, Mehta C, Patel N. MRI evaluation of lumbar disc degenerative disease. Journal of Clinical and Diagnostic Research. 2015 Apr;9(4):TC04-09. PMID: 26023617 DOI: 10.7860/JCDR/2015/11927.5761 [Publisher Full Text]

5. Hong SH, Choi J-Y, Lee JW, Kim NR, Choi J-A, Kang HS. MR imaging assessment of the spine: infection or an imitation? Radiographics. 2009 Apr;29(2):599-612. PMID:19325068 DOI: 10.1148/rg.292085137

6. Modic MT, Ross JS. Lumbar degenerative disk disease. Radiology. 2007 Oct;245(1):43-61. PMID: 17885180 DOI: $\underline{10.1148 / \text { radiol.2451051706 }}$

7. Okpala F. Measurement of Lumbosacral Angle in Normal Radiographs: A Retrospective Study in Southeast Nigeria. Annals of Medical Health and Science Research. 2014;4(5):757-62. PMID: 25328789 DOI: 10.4103/21419248.141548 [Publisher Full Text]

8. Been E, Kalichman L. Lumbar lordosis. The Spine Journal. 2014 Jan;14(1):87-97. PMID: 24095099 DOI: https://doi. org/10.1016/j.spinee.2013.07.464

9. Modic MT, Steinberg PM, Ross JS, Masaryk TJ, Carter JR. Degenerative disk disease: assessment of changes in vertebral body marrow with MR imaging. Radiology. 1988 Jan 1;166(1):193-9. PMID:3336678 DOI: 10.1148/ $\underline{\text { radiology.166.1.3336678 }}$

10. Gopalakrishnan N, Nadhamuni K, Karthikeyan T. Categorization of Pathology Causing Low Back Pain using Magnetic Resonance Imaging (MRI). Journal of Clinical and Diagnostic Research. 2015 Jan;9(1):TC17-20. PMID: 25738056 DOI: 10.7860/JCDR/2015/10951.5470 [Publisher Full Text]
11. Biluts $\mathrm{H}$, Munie $\mathrm{T}$, Abebe M. Review of lumbar disc diseases at TikurAnbessa Hospital. Ethiopian Medical Journal. 2012 Jan;50(1):57-65. PMID: 22519162

12. Dahal S, Joshi A, Pant S. Spectrum of Lumbar Spine Pathologies in Patients with Low Back Pain on MR Examination: A Retrospective Hospital Based Study. Post-Graduate Medical Journal of NAMS. 2015;12(02). [Publisher Full Text]

13. Ansari MA, Subedi K, Panta OB, Suwal S. MRI pattern of lumbosacral degeneration in Tribhuvan University Teaching Hospital, Nepal. Journal of institute of Medicine. 2015;38(2). [Publisher Full Text]

14. Ogon I, Takebayashi T, Takashima H, Tanimoto K, Ida $\mathrm{K}$, Yoshimoto M, et al. Analysis of chronic low back pain with magnetic resonance imaging T2 mapping of lumbar intervertebral disc. Journal of Orthopaedic Science. 2015 Mar 1;20(2):295-301. PMID: 25649736 DOI: 10.1007/ $\underline{\text { s00776-014-0686-0 }}$

15. Nardin RA, Patel MR, Gudas TF, Rutkove SB, Raynor EM. Electromyography and magnetic resonance imaging in the evaluation of radiculopathy. Muscle Nerve. 1999 Feb;22(2):151-5.PMID: 10024127

16. Sakamaki T, Sairyo K, Sakai T, Tamura T, Okada Y, Mikami H. Measurements of ligamentum flavum thickening at lumbar spine using MRI. Archives of Orthopaedic Trauma and Surgery. 2009 Oct;129(10):1415-9. PMID: 19280205 DOI: $\underline{10.1007 / \mathrm{s} 00402-009-0849-1}$

17. Saleem S, Aslam HM, Rehmani MAK, Raees A, Alvi AA, Ashraf J. Lumbar disc degenerative disease: disc degeneration symptoms and magnetic resonance image findings. Asian Spine Journal. 2013 Dec;7(4):322-34. PMID: 24353850 DOI: 10.4184/asj.2013.7.4.322 [Publisher Full Text]

18. Roudsari B, Jarvik JG. Lumbar spine MRI for low back pain: indications and yield. American Journal of Roentgenology. 2010 Sep 1;195(3):550-9. PMID: 20729428 DOI: $10.2214 /$ AJR.10.4367 [Publisher Full Text] 